\title{
Author Correction: New EU ETS Phase 4 rules temporarily puncture waterbed
}

\section{Grischa Perino}

Correction to: Nature Climate Change https://doi.org/10.1038/s41558-018-0120-2, published online 3 April 2018.

In the version of this Comment originally published, the scenario in which the market stability reserve (MSR) takes in allowances for seven years was calculated using incorrect $x$ and $y$ values in the formula described in the caption of Fig. 2; the red bars in Fig. 2 have now been updated. In the sentence "each subsequent year the number of allowances auctioned is reduced by $24 \%$ (12\% after 2024$)$ of the size of the bank" the year should have been 2023. These errors have now been corrected.
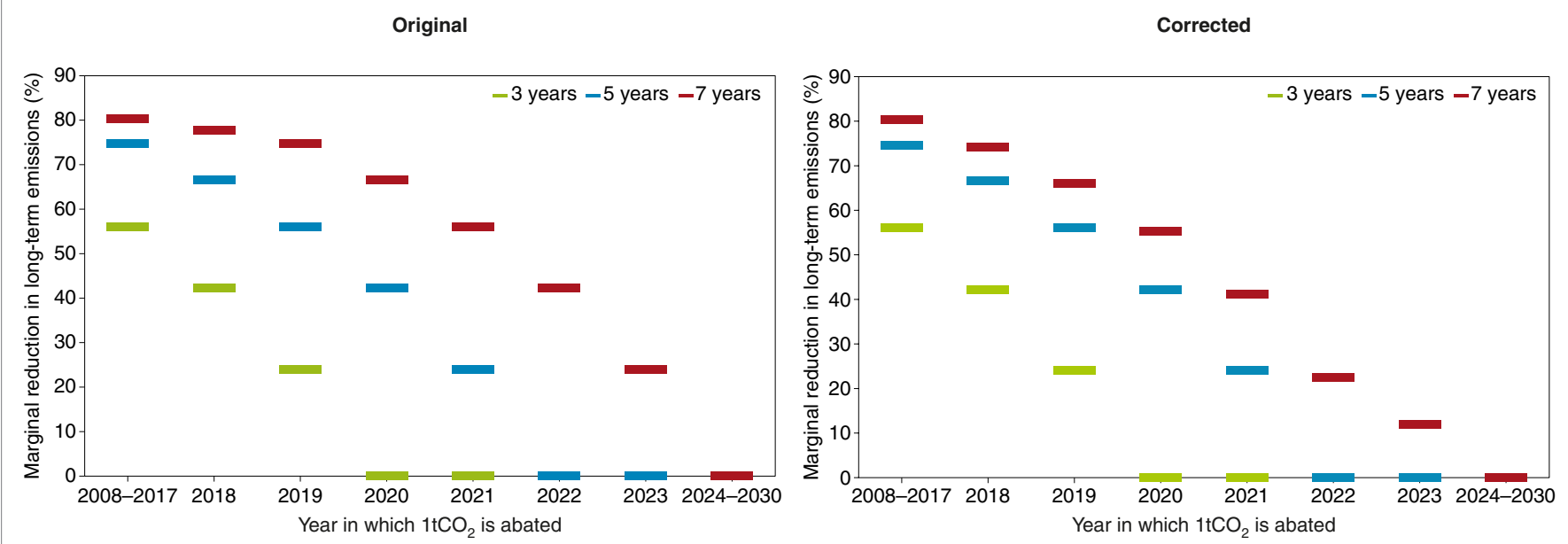

Fig. 2 | Original and Corrected.

Published online: 15 February 2019

https://doi.org/10.1038/s41558-019-0429-5 